\section{THE SURGICAL TREATMENT OF UTERINE MYOMA.}

Read in the Section of Obstetric Medicine and Gynacology at the Annual Meeting of the British Medical Assocration, July, 1890.

By LAWSON TAIT, F.R.C.S.,

Professor of Gynæcology in Queen's College, Birmingham.

AT the Cardiff Meeting of the British Medical Association (1885) I read a paper on the modern, and, as I ventured to add, the rational treatment, of myoma. ${ }^{1}$ In that paper I first of all showed that the method of treatment of this disease by the removal of the uterine appendages is an operation with a very low primary mortality. I gave a detailed list of cases operated upon since January 1st, 1884, 58 in number, without a death. The series preceding that consisted of 50 cases, with two deaths. I have since published ${ }^{2}$ another series of 219 cases, with 4 deaths. The three make one series of 327 consecutive cases, with 6 deaths, giving a percentage of mortality of 1.8 per cent.-a mere bagatelle of risk, and far less than the mortality of any other serious operation in surgery.

The primary mortality amply justifies the trial of this operation as a method of treatment of a disease which is painful, exhausting, and frequently fatal, but the establishment of the operation as a permanent addition to our surgical resources depends upon the ultimate and permanent effects of it, and these effects I now propose to prove in a way which has never before been done tor any other surgical proceeding, and I venture to say they will be found most satisfactory.

I have already ${ }^{3}$ shown for a large proportion of my cases the satisfactory results obtained, and after I have displayed the same for the rest of my series, I think it will be admitted that I have proved my thesis usque ad unguem, and that nothing further will be required in future.

For the statements concerning a few of the patients I am personally responsible, but the vast majority are made on the evidence of entirely independent witnesses, whose evidence is given in detail and in their own words, generally somewhat condensed, in order to minimise the space required for its production.

In order to save the time of such of my readers as do not care to wander through the mass of interesting detail, I may anticipate the evidence by what I have to say concerning my conclusions drawn from it. First of all, let me say that as each case can be easily identified in the following list with its corresponding publication in my previous papers and in my book by means of the dates and names of place of residence and of medical attendants, the old clumsy method of criticism-that my statements are untrue and my figures not to be relied upon-is at once rendered harmless. The method I employ makes it easy to test every case, and that is a method in striking contrast to that adopted by some of those who deal with the electrolytic method of treatment of myoma.

In Keith's recent book, the cases are so reported that they can be with difficulty identified, as, for instance, on page 207 I recognise the narrative of a patient upon whom I performed a successful hysterectomy only four months after she left Keith's hands. In reading his account of the case, an impression might be gathered that electrolysis was successful, but it was not-not even in giving temporary relief. Scattered through his pages are other instances in which I fancy I can identify patients upon whom I have successfully operated after the galvanic current had been used, but his method of recurd is such, that no certainty on this point can be arrived at.

The present series consists of 215 cases (219, less 4 deaths) whose lives have now extended, with a few exceptions, to a period of at, least twenty months since the operation. The history of many of the cases would prove that this period is not long enough to decide in any case where the progress is unsatisfactory that it will ultimately prove a failure. In the great bulk of the cases the process of cure begins at once, and is practically completed within six months. This is true of at least 90 per cent. of the

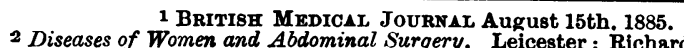

2 Diseases of Women and Abdominal Surgery. Leicester: Richardson and Co. cases, whilst in about 6 per cent. of the cases the cure is protracted over a period varying from twelve to thirty-six months.

Of the whole series of 321 , there are only five complete failures, that is, cases where the symptoms have been in no way relieved, and where the tumour has gone on growing, that is, the failure has been about $1 \frac{1}{2}$ per cent. But so far as the evidence yet to hand goes, the fault lies not in the operation, but in the imperfect way in which it was done.

Three of these failures have already been submitted to hysterectomy, and in all of them I found I had removed the ovaries completely, but in all of them one tube had been incompletely removed."

"Very careful examinations of the tumour were made, and we came to the conclusions that there was no aperture on the right cornu of the uterus, and that there was no trace of the right ovary or the tube. The aperture on the left cornu of the uterus was large enough to admit a No. 5 catheter, and there was more than two inches of the left Fallopian tube outside, which had not been removed at the original operation. No trace could be discovered of the left ovary. This ovary fortunately I had preserved, and when I re-examined the organ, which had been removed on January 4th, 1882, I found that its removal had been quite complete, but that only about one inch of the outer part of the Fallopian tube had been removed with it. Here, then, we have an extremely curious condition. The appendages on the right side were congenitally absent. The failure of the removal of the uterine appendages to arrest the growth of the tumour had always been regarded by me as due to the fact that the tumour was one of the soft cdematous myomata, and the case is alluded to in my recent paper in the BRITISH MEDICAL JouRnal as being the only real failure in my experience up to the date of that paper. Now, the evidence is to the effect that the failure was due, not to the peculiar nature of the tumour, but to the fact that I did not completely remore the only Fallopian tube which the patient possessed. In speaking of cases of myoma I have repeatedly referred to three cases in my experience where I have failed to arrest the growth of the tumours by removal of the appendages. In all these three I have regarded the reason of this failure as being due to the variety of the tumour-that of the œdematous myomata. In this, the first of the three cases in which I have had an opportunity of verifying the accuracy of my opinion, my view of the tumour has been correct, but it seems to me far more probable that the failure of my first operation was due to the incomplete removal of the tube than to the intrinsic quality of the tumour. I need not point out that this case goes a long way to show that removal of the ovaries has nothing to do with the brilliant results of these operations for bleeding myoma. As I have often said, in many cases I have deliberately left the ovaries, and yet success has been perfect. In this the ovary was absolutely removed, and the operation failed. This case is one of thirteen patients to whom I alluded in a speech made to the British Gynæcological Society. I hope to be able still further to reduce the list after such an encouraging experience."

The two others $(1,207$ and 1,284$)$ are coming back for the same purpose, and if I find that similar mistakes in the operation were made, then I am entitled to say that the operation has had no failures at all, but that the operator has had 5 .

One case (Dr. Halliday Croom's, 1,314) may be reckoned as a failure, but the evidence is incomplete as there was no postmortem examination, and I am disposed to believe that it was rather an instance of mistaken diagnosis than of failure, and that the patient was suffering not from myoma but from endometric cancer. In my whole series there have been three such mistakes (less than 1 per cent.), and I do not see how they are ever to be entirely avoided. They certainly must not be put down to failure of the operation.

Of incomplete or unsatisfactory results $I$ have to indicate 5 cases. Two cases died respectively seven and eight weeks after their recovery and after leaving my care, the deaths being returned in both instances as due to typhoid fever. In one case $(1,662)$ the patient died six months after the operation from the condition of extreme anæmia into which her hæmorrhage had reduced her. It will be seen that her medical attendant expresses a strong opinion that a complete cure was not reached only because the operation was done too late. The remaining cases $(1,803$ and 1,971$)$, with unsatisfactory histories, are two which I fear might be put down as deaths due to the operation, if we knew the full facts of the endings. In the first case recovery 4 British Medical Journal, October 3rd, 1885. 
from the operation was perfect, yet she died instantaneouslyprobably from heart clot-when on her homeward journey, and after she had been going about for nearly a week; and in the other, suppuration in the right inguinal region was the indirect cause of death seventeen montbs after the operation, and this probably originated indirectly from the operation.

This leaves 311 cases in which complete cures have been effected-that is to say, in which the symptoms have been satisfactorily relieved-where the tumour has either entirely disappeared or has so diminished or has been so satisfactorily arrested as to be no longer a source of anxiety or trouble, and where the main feature of the disease, exaggerated menstruation, has been completely and permanently arrested.

Upon the subject of the applicability of this operation-removal of the uterine appendages for the treatment of a certain class of uterine myoma-I have been in hesitation for some considerable time. At one time I had almost made up my mind that for the treatment of the soft œedematous variety it would not prove available, but I have had abundant proof of late years to alter that opinion. There can be no question that in joung subjects removal of the appendages is as efficacious for the soft cedematous solitary variety as it is for the multinodular hard variety : and of the 5 cases in which failure has taken place, only 2 belong to the soft œdematous order; the other 3 belong to the multinodular. The only objection, however, that I find to the performance of this operation is the occasional difficulty of its completion, and this, of course, is a matter which will vary in the hands of different operators according to their individual expertness. One man will fail to remove the appendages in a case where another will succeed. There can, however, be no question that there will always be a certain proportion of cases in which removal of the appendages will be practically an impossibility. Looking over the list of cases in which I have performed hysterectomy during the period over which the present list extends, I think that the present proportion of cases where I have been unable to perform the operation of removal of the appendages, and have had to complete the case by hysterectomy, amounts to about 4 per cent. In a considerable number of other cases I deliberately performed hysterectomy on account of the enormous size of the tumours, having the belief that the removal of the appendages in such huge masses would be almost as risky as removal of the masses themselves.

I have also deliberately performed hysterectomy in growing œdematous myoma where menstruation had ceased, as in such cases removal of the appendages was manifestly contraindicated.

Concerning the disappearance of tumours after the removal of the appendages and the arrest of menstruation, there can be no doubt whatever that the youth of the patient has a great deal to do with the activity of the process and the extent to which it is carried out. I cannot give the figures which will yield an exact indication of this result, but $I$ think it may be very fairly expressed as follows: That under 40 years of age about 70 per cent. of the tumours entirely disappear. Between 40 and 45. as a rule, they do not disappear entirely, but become markedly diminished, and after 45 the diminution is only a shrinking, running between one-third and one-sixth of the bulk of the mass. There have been in my experience, however, remarkable exceptions to this latter conclusion, as I have seen a tumour much larger than an adult head disappear in a woman between 49 and 50 after the operation. The ages of many of the patients on the list will indicate very clearly the erroneous belief which exists in the professional mind that the approach of the age at which the menopause usually takes place gives anything like certain relief in cases of myoma, for no fewer than 9 of the cases were upwards of 50 years at the time of the operation.

A curious result was obtained in 3 of the cases during the process of cure, a result which might have been anticipated as likely to occur in a certain proportion of caser, but which came upon me as a surprise. It was that during the absorption of the tumour, a piece, which I assume had had an intrauterine existence as a polypus before the operation, came to be extruded as the accomplishment of that process became possible after the absorption of the main bulk of the tumour. The polypus, as it were, formed a remanet in the cavity of the uterus which could be extruded only after the walls had resumed their normal condition. When extruded it was easily removed in the ordinary way. In these three cases the hæmorrhage went on persistently till the extrusion of the polypus and its removal, so that for some considerable time they all looked as if they would be failures. In one case $(1,276)$ the patient has become a complete neurasthenic, but her tumour and the symptoms arising therefrom are completely cured. It may be that her neurasthenia is the result of the operation, but $I$ know of no indication which justifies this conclusion. With one other exception, this is the only case in which nervous symptoms. have supervened to any serious extent since the operation. During the process of the climacteric several of my patients became queer for a short time-that is, they were eccentric and ill-tempered, but nothing was more marked in these respects than we often have in women during the normal change of lif $\theta$; in fact, I should say, on the whole, there has been a good deal less of this among these thirty women than if they had been going through the normal climacteric.

A question has recently been raised by Dr. Thomas Keith concernivg the occurrence of insanity after grave operations upon the uterus, particularly hysterectomy, and he has made the statement that it occurs in the proportion of 10 per cent. of the cases. This can only bo explained as a clerical error or an exceptional result, for it is wholly unsupported by the evidence of anyone else who has written on the subject. I have operated upon a very much larger number of cases of hysterectomy than Dr. Keith has done, and I know of no case of insanity in my practice. Instances of insanity occur after all surgical proceedings, even the most trivial, and even after the administration of an anæsthetic, without any operation at all.

In the present list of cases one patient alone, so far as I know, hos been committed to an asylum, and she is there now (Case 1,453). On reading the report of the case, it is quite clear that the woman was perfectly incane before the operation, and Dr. Marriott Cocke, of Worcester, under whose care she is at the present moment, sees no reason whatever to attribute her insanity to the result of the operation. But even if it were to be so attributed, there are three cases in the list in which, for reasons which must be evident, I cannot indicate, acknowledged insanity of the most pronounced type has been completely cured by the relief of the sufferings involved by the bæmorrhagic myoma; and, in addition to these three cases of pronounced insanity which have been completely and, so far as we can see, permanently cured, there are a number of cases of striking eccentricities and ill-temper which have been clearly due to the sufferings, and which have been equally reprieved.

It may be in future, when the method of research which I have initiated in this particular operation is extended to others, that a very much enhanced value may be credited to a large number of our surgical proceedings; but, so far as we have gone, I think it: would be very difficult indeed to bring forward instances in which it is at all likely that a higher value could be attained by any operation than in the present instance. The operation not only relieves but permanently and completely cures the sufferings of the disease against which it is directed, and I think it must be admitted as one of the most brilliant additions to modern surgery of which we have any knowledge. That there will be a number of cases of myoma for which it will be inapplicable I know already, but when it becomes the uniform practice to submit all cases of myoma requiring treatment to this safe, prompt, and effectual measure, and to apply the treatment in the early stages of the disease instead of losing valuable time in measures wholly ineffectual and far more dangerous, the number of cases requiring the more serious operation of hysterectomy will reach an almost vanishing point.

This series of cases also offers very abundant proof that the removal of the ovaries has nothing whatever to do with the question of the arrest of menstruation. Menstruation is a rhythmical process, and therefore clearly governed by a special nerve mechanism. Ovulation, on the contrary, does not seem to be a rhythmical process, but occurs at irregular periods, and probably therefore is no more the result of nerve influence than any other gland function, that is to say, there is probably no special nerve system governing it. In a great many instances where the ovaries have been completely remóved menstruation has gone on perfectly regularly for many months, and in the list now submitted there are thirteen cases in which the ovaries were not removed at all, and fire in which only one was removed; yet in sixteen out of the eighteen cases menstruation Jas immediately arrested, occurring only once in each instance after the operation, and in the other two cases it went on for about five and eight months respectively. In all cases the greatest care has been exercised to remove the Fallopian tubes completely.

I am now of opinion that it is not so much the removal of the tubes as the destruction of a nerve which lies between the tube and the round ligament of the uterus, which is probably the 
efferent nerve goperning the periodicity of the phenomena of menstruation. The evidence of the whole series is certainly entirely without exception in favour of the view which I have held almost ever since I began to study the question of the Fallopian tube as having more to do with the function of menstruation than the ovaries, that in fact the ovaries have nothing whatever to do with it at all, and the tube has this at least, it is the subject in which the initial phases of the phenomena occur.

[Notz. - The detailed statement of cases which accompanied this paper is omitted for want of room. It is Mr. Tait's intention to republish this article, together with the cases, in a pamphlet which will shortly be iseued.]

Dr. LAWRENCE considere 1 that the electric treatment should be tried in every c a $3 \theta$ of myoma uteri before any surgical proceeding, if there was no pelvic disease besides the myoma uteri to contraindicate the necessary manipulation. In cases where, after a trial of six to eight applications, the bleeding still continued excessive, or the tumour continued to grow, then he would proceed either to removal of appendages or the uterus itself.-Dr. BANTOCK had great pleasure in supporting Mr. Lawson Tait in his advocacy of this method of treatment. One point omitted by him was that there seemed to be two forms of myoma, in one of which the operation was of eminent service, the other in which it appeared to be of little $u s e$. The first was the hard variety, and the second was the soft. Experience had now taught him to set aside the latter class for absolute removal. One advantage of this operation over the electrolytic treatment was that when the tumour disappeared it did so by an imitation of Nature's process; whereas in the case of the disappearance of a tumour by the electrical treatment, in the majority of cases the process had been characterised by the most serious symptoms arising from a destructive process of acute degeneration.-Dr. HEYwood SMITH did not desire to make any remarks on the main subject of Mr. Lawson Tait's paper except to observe that by his brilliant results, not only in the very small mortality, but also in the permanent results, Mr. Tait had established this operation for fibroids. He (Dr. Smith) wished to call attention to what Mr. Tait had said on cases of insanity, and quite thought that it was desirable to appoint a gynæcologist to all lunatic asylums. He wished to refer to a recent case, which he hoped at some future time to relate more in detail and after a longer interval had elapsed since the operation. This patient had been under an alienist for more than a year with, as was said, "intermittent melancholia." These attacks lasted often some months, during which she was wholly unfit to go into society, and though when she came out of them she was a bright lively girl, yet she was in continual apprehension of a recurrent attack. He removed the oraries in February, since which time she had been perfectly free, and had gone home well.

\section{MEMORANDA: \\ MEDICAL, SURGICAL, OBSTETRICAL, THERA- PEUTICAL, PATHOLOGICAL, ETc.}

PLACENTA PRAVIA: RECOVERY.

S. A. B., aged 26 , third pregnancy. Six weeks ago "flooding" set in, and coutinued in small quantities from that time till the date of her confinement, Saturday, August 23rd, with the interval of two days between each attack. In addition to the usual symptoms indicative of loss of blood she suffered from severe and violent vomiting each time flooding came on, and on these occasions was completely unconscious. For the flooding she was attended by a local medical gentleman; in the absence of this gentleman from home I was sent for on the above date.

On examination, I found the os fairly well dilated, soft and yielding ; placenta adherent to posterior left and anterior border of internal os; hæmorrhage rather free. She was exceedingly feeble, and was unconscious for a considerable time before my arrival. The pulse was scarcely perceptible, and the face was deadly pale. Seeing the condition of things, and believing that delay would seriously imperil her life, I determined to deliver with all possible despatch. With this view I introduced my right hand into the vagina (having rendered it, of course, aseptic), and with the middle and index finger completely separated the placenta from its attachment; I then forcibly dilated the os. A strong and vigorous contraction set in while dilating the os, which produced the expulsion of the placenta into the vagina. During all this time brisk friction was maintained at the fundus of the uterus. After rupture of the membrane I applied.the short forceps as soon as the os was sufficiently dilated to admit of its passage, and immediately delivered the child, needless to say stillborn.

What struck me most in this case was the complete cessation of hæmorrhage after separation of the placenta. I have thought it well to report this case, as the above treatment may prove serviceable to young practitioners who may have to deal with similar ones. The great thing for the young physician in those cases is to keep his eyes open and his head clear.

Macclesfield. W. A. MACMAHON GARRY, L.R.C.P.I., etc.

PROLAPSE OF THE URETHRA IN FEMALE CHILDREN. Not long ago this condition, and its treatment, were discussed in the BrItish Mrdical Journal. A case which was under my care in the Hospital for Sick Children may serve as an illustration.

A child, then aged about 9 years, was brought to me on account of an abnormal appearance of the orifice of the urethra, which the mother had observed. There was some muco-purulent discharg $\theta_{*}$ but no pain. On examination, I found what appeared to be a growth about the siz $\rightarrow$ of a cherry stone. It was brighter red than the surrounding mucous membrane. The urethral canal was in the centre of it. It was clearly made up of the mucous membrane of the urethra, protruded and swollen.

The treatment was simple. Under chloroform, as much as seemed necessary of the prolapsed mucous membrane was removed with scissors, the cuts being made in a direction radiating outwards from the meatus. The cautery was lightly applied to stop bleeding. From fear of producing stricture, rather too little tiosue was removed at first. After a fow weeks it was found necessary to put the child under chloroform again, and remove a little more of the. mucous membrane. This was done in January last, and apparently the result is entirely satisfactory. I bad lately an opportunity of examining the child. There was no,return of the prolapse, and there has never been any difficulty in micturition.

Fredraic C. Coley, M.D.,

Physician to the Hospital for Sick Children, and to the Northern Counties Hospital for Diseaces of the Chest, Newcastle-on-Tyne.

TWO CASES OF CHOLERA NOSTRAS.

r. ON Saturday, August 23rd, 1890, E. H., aged 67, farm labourer, Greetland, near Halifax, was mowing corn all day from 9 A.M. until 6 P.M. He then returned home, washed and dressed himself, and set off to West Vale, about three-quarters of a mile, for his week's provisions. About 10 o'cloci on the same night he had a copious watery evacuation, nothing, as he said, like what he had ever had before. A second motion occurred soon after, and after returning to the house this time he began to vomit, these calls becoming so frequent he was unable finally to leave the house. After continuing for an hour and a half or two hours cramp of the buttocks, thighs, and legs set in. These symptoms continuing all night, I was called in on Sunday morning, August $24 \mathrm{th}$, and found him in a state of collapse, pulseless, and only able to speak in whispers. There was lividity, cold skin and breath; the tongue was white, the cramps were now extending to the arms, there were rice-water evacuations, $\epsilon x c e s s i v e$ thirst, he was complaining of great heat, and vomiting was continuous.

I pronounced it a case of cholera. Brandy was injected hypodermically and hot bricks were placed at his side, and a good strong dose of sp. ammon. co. was given every half hour. He rallied a little-at least, he was warmer on my return later in the day. As he was still pulseless, I injected brandy again, with half a grain of morphine this time. The cramps partly abated then, and he felt somewhat easier. I ordered a large bran poultice over abdomen and chest, which gave great relief.

On Sunday night he began to ramble. On Monday morning, however, he was better, and the pulse could now be felt, 136 a minute, and the spssms bad entirely ceased for some hours. I then wired to Dr. Hime, Bradford, and he came out and confirmed my diagnosis, at the same time taking some of the dejecta with him. for further examination.

On Tuesday morning he was still improving, pulse now 96, and feeling better himself. This improvement lasted until Tuesday night, about 6 o'clock, when he began to get worse, subsultus tendinum, etc. 